\title{
Significance of umbilical artery doppler velocimetry in the perinatal outcome of growth restricted fetuses
}

\author{
Jyothi Susan Thomas $^{1 *}$, A. Malliga ${ }^{1}$, S. Sethurajan ${ }^{2}$
}

\begin{abstract}
${ }^{1}$ Department of Obstetrics and Gynecology, ${ }^{2}$ Department of Radiodiagnosis, Rajah Muthiah Medical College and Hospital, Chidambaram, Tamil Nadu, India
\end{abstract}

Received: 07 January 2018

Accepted: 03 February 2018

\section{*Correspondence:}

Dr. Jyothi Susan Thomas,

E-mail: dr.jyothisusan@gmail.com

Copyright: (c) the author(s), publisher and licensee Medip Academy. This is an open-access article distributed under the terms of the Creative Commons Attribution Non-Commercial License, which permits unrestricted non-commercial use, distribution, and reproduction in any medium, provided the original work is properly cited.

\begin{abstract}
Background: The objectives of the study are to determine the relationship between the umbilical artery Doppler and perinatal outcome in growth restricted fetuses and to compare the outcome with those of normal fetuses.

Methods: A prospective observational study in which subjects were divided into two groups, pregnancies affected with intrauterine growth restriction (IUGR) and pregnancies with normal fetuses. Both the groups were followed with Doppler velocimetry of umbilical artery after 28 weeks till delivery. The perinatal outcome of both the groups with normal and abnormal umbilical artery Doppler (reduced/ absent/ reversed end - diastolic flow) were analysed with Chi-square test and student $\mathrm{t}$ - test using SPSS software version 15.0.

Results: Umbilical artery Doppler velocimetry showed significant abnormality in growth restricted foetuses in comparison to normal foetuses. There was significant increase in the delivery of IUGR foetuses $<37$ weeks gestation $(\mathrm{p}<0.05)$. There was a significant increase in operative deliveries in both the groups with abnormal umbilical artery Doppler. A significant rise in adverse perinatal outcomes, Apgar $<7$ at $5 \mathrm{~min}$ and low birth weight in IUGR foetuses in comparison to normal foetuses $(\mathrm{p}<0.05)$.

Conclusions: There is a strict correlation between abnormal umbilical artery Doppler velocimetry and an increased incidence of perinatal complications in growth restricted foetuses compared to normal foetuses. Hence, umbilical artery Doppler velocimetry should be used in all patients with fetal growth restriction, to identify impending hypoxia, to optimise the time of delivery and to optimise the perinatal outcome in these patients.
\end{abstract}

Keywords: Fetal growth restriction, Perinatal outcome, Umbilical artery doppler

\section{INTRODUCTION}

Intrauterine Growth Restriction (IUGR) is defined as a condition where the fetus fails to achieve its growth potential with estimated weight below the $10^{\text {th }}$ percentile for their gestational age. The incidence of IUGR is $3-10 \%$ of all births. ${ }^{1}$ Next to prematurity, IUGR is the second leading cause of perinatal mortality. Compared with appropriately grown counterparts, perinatal mortality rates in growth restricted fetuses are 6 to 10 times greater; perinatal mortality rates as high as 120 per1000 for all cases of IUGR and 80 per 1000 after exclusion of anomalous infants have been reported. The incidence of fetal demise, birth asphyxia, meconium aspiration, neonatal hypoglycemia and hypothermia are all increased, as is the prevalence of abnormal neurological development. ${ }^{2,3}$ IUGR is a sign of chronic hypoxemia. IUGR is seen even when $40 \%$ of tertiary villi are affected whereas abnormal umbilical artery waveforms are seen only when $70 \%$ of tertiary villi are affected. Hence, umbilical artery Doppler cannot be used as a screening test for IUGR. However, umbilical artery Doppler has the 
capacity to find those IUGR fetuses that are truly at risk of developing birth asphyxia and therefore need surveillance.

\section{METHODS}

A prospective observational study conducted in a tertiary care teaching hospital from 2011-2013.One hundred documented IUGR cases confirmed by clinical evaluation and serial ultrasound biometry and one hundred normal (non-IUGR) controls matched for age and parity were selected for the study. Singleton fetuses with normal fetal anatomy were included in the study. Patients with a history of irregular cycles and unknown dates, with maternal infection, with a history of bleeding per vaginum of unknown cause and those with fetal anomalies were excluded from the study. A detailed history taking and examination of the antenatal patients fulfilling the above mentioned criteria was done. Those patients with fundal height less than $3 \mathrm{~cm}$ from the expected height were clinically diagnosed as IUGR and ultrasound examination was done with special emphasis on morphometric measurements. The ultrasonographic examination of biometry and umbilical artery Doppler was done from 28 weeks gestation with Siemens model probe $5-7.5 \mathrm{MHz}$. Abdominal circumference less than the 5th percentile and estimated fetal weight less than the 10th percentile for that gestational age were diagnosed as IUGR fetuses. The umbilical cord was located in the pool of amniotic fluid and umbilical artery doppler velocimetry was done at the mid cord and angle of insonation adjusted to less than $60^{\circ}$.All recordings were preferably obtained when there were no fetal breathing movements and with the fetal heart rate between 120 and 140 beats per minute. The signals were recorded for a minimum of $5-8$ cycles with blood flow velocity waveforms of equal shape and amplitude and of satisfactory quality were obtained. Doppler was considered abnormal when there was absent or reversal of end diastolic flow in the umbilical artery or PI values were above the 95th percentile for that gestational age. Those cases where the fetal assessment was normal were monitored fortnightly till delivery and those with abnormal umbilical artery Doppler were monitored weekly/biweekly depending on the severity. Pregnancies with absent and reversal of end - diastolic flow were terminated.

All pregnancies were under surveillance till delivery by monitoring daily fetal movement count, non stress test, serial biometry, biophysical profile and Doppler studies. The mode of delivery was planned depending on the fetal weight, gestational age, presentation, the amount of liquor and umbilical artery Doppler. Perinatal outcomes were recorded in detail including birth weight, Apgar score, intrauterine death, neonatal death and development of neonatal complications. The data was analyzed by Chi - square test and student ' $t$ ' test for non parametric and parametric variables respectively using SSPS software.

\section{RESULTS}

Table 1: Maternal characteristics and outcome in both groups.

\begin{tabular}{|c|c|c|c|}
\hline Characteristics & IUGR & Normal & P-value \\
\hline \multicolumn{4}{|l|}{ Age (years) } \\
\hline$<20$ & $15(15 \%)$ & $9(9 \%)$ & \\
\hline $20-30$ & $74(74 \%)$ & $83(83 \%)$ & 0.28 \\
\hline$>30$ & $11(11 \%)$ & $8(8 \%)$ & \\
\hline $\begin{array}{l}\text { Mean age in } \\
\text { years }\end{array}$ & 25.13 & 25.56 & \\
\hline \multicolumn{4}{|l|}{ Parity } \\
\hline Primigravida & $54(54 \%)$ & $53(53 \%)$ & 0.87 \\
\hline Multigravida & $46(46 \%)$ & $47(47 \%)$ & \\
\hline \multicolumn{4}{|c|}{ Timing of delivery (weeks) } \\
\hline $32-34$ & $6(6 \%)$ & $3(3 \%)$ & $<0.001$ \\
\hline $35-37$ & $51(51 \%)$ & $19(19 \%)$ & \\
\hline$>38$ & $43(43 \%)$ & $78(78 \%)$ & \\
\hline
\end{tabular}

Table 2: Mode of delivery based on the umbilical artery velocimetry in both groups.

\begin{tabular}{|c|c|c|c|c|c|}
\hline \multirow{2}{*}{ Mode of delivery } & \multicolumn{2}{|l|}{ IUGR } & \multicolumn{2}{|l|}{ Normal } & \multirow[t]{2}{*}{ p- value } \\
\hline & Normal doppler & Abnormal doppler & Normal doppler & Abnormal doppler & \\
\hline \multicolumn{5}{|l|}{ Vaginal delivery } & \multirow{4}{*}{0.012} \\
\hline Spontaneous & 12 & 8 & 25 & 1 & \\
\hline Instrumental & 4 & 3 & 4 & 1 & \\
\hline LSCS & 25 & 48 & 45 & 24 & \\
\hline
\end{tabular}

The study was conducted on 200 cases out of which 100 pregnancies with ultrasonographically confirmed IUGR fetuses and 100 pregnancies with normal fetuses were selected for the study. There was no major difference in the maternal age and parity between mothers of both groups. Age of majority of the patients ranged between 20- 30 years in both the groups (IUGR $-74 \%$ and normal fetuses $-83 \%$ ). The majority were primigravida (IUGR $54 \%$ and normal $-53 \%$ ) (Table 1$)$.

This led to a majority of the IUGR fetuses being delivered $<37$ weeks (49\%) when compared to normal fetuses, a majority of whom were delivered $>37$ weeks (78\%) (Table 1). 
There was a significant abnormality in umbilical artery Doppler in IUGR (59\%) in comparison to normal fetuses (26\%) (Table 3).

Table 3: Distribution based on the umbilical artery doppler for the two groups.

\begin{tabular}{|c|c|c|c|}
\hline $\begin{array}{l}\text { Umbilical artery } \\
\text { doppler }\end{array}$ & IUGR & Normal & $\begin{array}{l}\text { p- } \\
\text { value }\end{array}$ \\
\hline Normal & $41(41 \%)$ & $74(64.3 \%)$ & \multirow{4}{*}{$<0.001$} \\
\hline Reduced & $49(49 \%)$ & $24(32.9 \%)$ & \\
\hline AUADF & $8(8 \%)$ & $2(2 \%)$ & \\
\hline RUADF & $2(2 \%)$ & $0(0 \%)$ & \\
\hline
\end{tabular}

Frequently, fetuses with abnormal Doppler were delivered by cesarean section in both the groups (Table 2). These neonates had lower birth weight percentiles. Mean birth weight in IUGR was $1.99 \mathrm{~kg}$, the standard deviation was 0.35 and mean birth weight in normal fetuses was $2.91 \mathrm{~kg}$, the standard deviation is 0.32 . Both were compared with t- value $19.23, \mathrm{p}-$ value $<0.001$ (Table 4).

Table 4: Comparison of the perinatal outcomes in both the groups based on the umbilical artery doppler.

\begin{tabular}{|c|c|c|c|}
\hline Perinatal outcomes & IUGR & Normal & $\begin{array}{l}\text { p- } \\
\text { value }\end{array}$ \\
\hline \multicolumn{4}{|c|}{ Birth weight (in grams) } \\
\hline $1000-1400$ & $8(8 \%)$ & $0(0 \%)$ & \multirow{4}{*}{$<0.001$} \\
\hline $1500-1900$ & $32(32 \%)$ & $0(0 \%)$ & \\
\hline $2000-2400$ & $54(54 \%)$ & $5(5 \%)$ & \\
\hline$>2500$ & $6(6 \%)$ & $95(95 \%)$ & \\
\hline $\begin{array}{l}\text { Mean birth weight (in } \\
\text { grams) }\end{array}$ & 1990 & 2910 & \\
\hline $\mathrm{APGAR}<7$ at $5 \mathrm{~min}$ & $55(55 \%)$ & $12(12 \%)$ & $<0.001$ \\
\hline \multicolumn{3}{|l|}{ NICU admissions } & \multirow{5}{*}{$<0.001$} \\
\hline Normal & $12(12 \%)$ & $6(6 \%)$ & \\
\hline Reduced & $37(37 \%)$ & $5(5 \%)$ & \\
\hline AUADF & $7(7 \%)$ & $2(2 \%)$ & \\
\hline RUADF & $1(1 \%)$ & $0(0 \%)$ & \\
\hline \multicolumn{3}{|l|}{ IUD } & \multirow{3}{*}{$<0.001$} \\
\hline AUADF & $1(1 \%)$ & $0(0 \%)$ & \\
\hline RUADF & $1(1 \%)$ & $0(0 \%)$ & \\
\hline \multicolumn{3}{|l|}{ NND } & \multirow{3}{*}{$<0.001$} \\
\hline AUADF & $2(2 \%)$ & $0(0 \%)$ & \\
\hline RUADF & $1(1 \%)$ & $0(0 \%)$ & \\
\hline
\end{tabular}

*IUD: Intrauterine death, NND: Neonatal death

There were 2 intrauterine deaths and 3 neonatal deaths among the IUGR fetuses with absent/ reversed end diastolic flow in umbilical artery Doppler (Table 4).

There was a significant rise in the adverse perinatal outcomes in IUGR fetuses compared to normal fetuses. Low Apgar score $<7$ at 5 minutes was significantly higher in the IUGR fetuses with abnormal Doppler (Table $5)$.
There was a comparative rise in the NICU admissions among the IUGR fetuses in view of birth asphyxia, meconium aspiration syndrome, hypoxic ischemic encephalopathy, neonatal sepsis neonatal jaundice (Table $6,7)$.

TABLE 5: Distribution of cases with apgar score $<7$ at 5 min based on umbilical artery doppler in both groups.

\begin{tabular}{|llll|}
\hline Doppler & $\begin{array}{l}\text { IUGR } \\
(\mathbf{n}=55)\end{array}$ & $\begin{array}{l}\text { Normal } \\
(\mathbf{n = 1 2})\end{array}$ & \multirow{2}{*}{ p- value } \\
\cline { 1 - 3 } Normal & $9(16.4 \%)$ & $5(41.7 \%)$ & \\
\hline Reduced & $36(65.5 \%)$ & $5(41.7 \%)$ & \\
\cline { 1 - 3 } AUADF & $8(14.5 \%)$ & $2(16.6 \%)$ & $<0.001$ \\
\hline RUADF & $2(3.6 \%)$ & $0(0 \%)$ & \\
\hline
\end{tabular}

Table 6: Distribution of perinatal morbidities in IUGR fetuses.

\begin{tabular}{|lllll|}
\hline Doppler & $\begin{array}{l}\text { Normal } \\
(n=12)\end{array}$ & $\begin{array}{l}\text { Reduced } \\
(\mathrm{n}=37)\end{array}$ & $\begin{array}{l}\text { AUADF } \\
(\mathrm{n}=5)\end{array}$ & $\begin{array}{l}\text { RUADF } \\
(\mathrm{n}=1)\end{array}$ \\
\hline $\begin{array}{l}\text { Birth } \\
\text { asphyxia }\end{array}$ & $6(50 \%)$ & $27(73 \%)$ & $4(80 \%)$ & 0 \\
\hline TTN & $4(33.3 \%)$ & $5(13.5 \%)$ & 0 & 0 \\
\hline MAS & 0 & $3(8.1 \%)$ & 0 & 0 \\
\hline HIE & 0 & $1(2.7 \%)$ & $1(20 \%)$ & $1(100 \%)$ \\
\hline $\begin{array}{l}\text { N. } \\
\text { Sepsis }\end{array}$ & $2(16.7 \%)$ & 0 & 0 & 0 \\
\hline $\begin{array}{l}\text { N. } \\
\text { Jaundice }\end{array}$ & 0 & $1(2.7 \%)$ & 0 & 0 \\
\hline
\end{tabular}

Table 7: Distribution of perinatal morbidities in normal fetuses.

\begin{tabular}{|lllll|}
\hline $\begin{array}{l}\text { Doppler } \\
\text { Birth }\end{array}$ & $\begin{array}{l}\text { Normal } \\
(\mathbf{n}=6)\end{array}$ & $\begin{array}{l}\text { Reduced } \\
(\mathbf{n}=5)\end{array}$ & $\begin{array}{l}\text { AUADF } \\
(\mathbf{n}=2)\end{array}$ & $\begin{array}{l}\text { RUADF } \\
(\mathbf{n}=\mathbf{0})\end{array}$ \\
$\begin{array}{l}3(50 \%) \\
\text { TTN }\end{array}$ & $1(20 \%)$ & $2(100 \%)$ & 0 \\
\hline MAS & 0 & $3(60 \%)$ & 0 & 0 \\
\hline HIE & 0 & $1(20 \%)$ & 0 & 0 \\
\hline $\begin{array}{l}\text { N. } \\
\text { Sepsis }\end{array}$ & $1(16.7 \%)$ & 0 & 0 & 0 \\
\hline $\begin{array}{l}\text { N. } \\
\text { Jaundice }\end{array}$ & 0 & 0 & 0 & 0 \\
\hline
\end{tabular}

*TTN: Transient tachypnea of newborn, MAS: Meconium aspiration syndrome, HIE: Hypoxic ischemic encephalopathy, N. Sepsis: neonatal sepsis, N. Jaundice: neonatal jaundice

\section{DISCUSSION}

Fetometry by B- Mode ultrasound is a reliable method of investigation to distinguish between IUGR and normal fetuses. However, the B-Mode ultrasound did not reliably detect the adverse perinatal outcome. The umbilical artery Doppler velocimetry has important prognostic significance. The predictive capability of Doppler of adverse perinatal outcome was analyzed in ultrasonographically confirmed IUGR cases were analyzed. Both IUGR and normal fetuses with abnormal 
umbilical artery Doppler had increased perinatal morbidity and mortality, with the IUGR fetuses in this subgroup having the poorest prognosis. Newham et al evaluated the efficacy of Doppler flow velocity waveform analysis as a screening test in pregnancy. ${ }^{4}$ They found that prediction of fetal hypoxia by Doppler analysis was enhanced in IUGR fetuses, where it was weak when umbilical artery PI values were evaluated as primary screening tests for fetal hypoxia. These finding very much conform to our observations. The explanation for these observations is probably that fetal growth restriction can be either due to low intrinsic growth potential or due to defective placental nutritive and circulatory functions, of which Doppler can investigate only the circulatory component. There is a significant decrease in the PI of the umbilical artery as the birth weight increases, the birth weight being higher in the normal Doppler group and lowest in the absent/ reversed end diastolic flow group. This is in accordance with Fleischer et al who demonstrated that those foetuses with lower birth weight $\left(<25^{\text {th }}\right.$ percentile) had higher placental vascular resistance than those foetuses with lower birth weight. ${ }^{5}$ In a study conducted by Malhotra et al, among the IUGR foetuses birth weight in abnormal Doppler group was $742 \pm 126 \mathrm{~g}$ and in normal Doppler group was $1680 \pm 259$ g. $^{6}$ In our study the IUGR foetuses birth weight in the abnormal group was between 1500-1900g and in normal Doppler group was between 2000-2400g. In consonance with our study Vergani et al demonstrated that Doppler PI of umbilical artery independently predicts the likelihood of NICU admission for reasons other than low birth weight. ${ }^{7}$ Conversely, the study of Mc Cowan found that the effect of abnormal umbilical artery Doppler was not important in terms of admission of the newborn to the NICU, birth weight and gestational age. ${ }^{8}$ The results of our study show that fetuses with IUGR associated with abnormal umbilical artery velocimetry have an early delivery, increased NICU admission, need for PPV, low Apgar score than those with normal Doppler. Perinatal mortality was highest in the absent and reversed end diastolic flow group. Various studies also suggest that the most extreme waveform abnormality, that is RUADF or AUADF which is considered a very ominous sign of placental compromise and is associated with high perinatal mortality rates. Increased incidence of cesarean section was found in patients with abnormal umbilical artery Doppler but there was no difference between the IUGR and normal fetuses as the cesarean section was done for other indications like CPD, contracted pelvis, scar tenderness, scar rupture, eclampsia. A reduction in the rate of velocity of fetal growth detected by serial ultrasonic fetal anthropometry is related to caesarean delivery for fetal distress and significant fetal growth restriction..$^{9,10}$

Our study underlines the existence of a strict correlation between umbilical artery Doppler and an increased incidence of perinatal complications in IUGR foetuses, in consonance with the study of Soregaroli et al. ${ }^{11}$ Similar results were drawn by Baschat when they looked at the umbilical artery resistance to determine if it can improve the accuracy of diagnosing IUGR and help in identifying a small fetus at risk of chronic hypoxemia. ${ }^{12}$ Doppler velocimetry studies of the umbilical artery can distinguish the group of IUGR fetuses at risk of complications thereby helps to improve the fetal outcome. The application of nonstress test and biophysical scoring should guide the evaluation of such women for timing the delivery. Fleischer et al have pointed out the role of venous Doppler studies in assessing the degree of hypoxemia and in guiding the correct time for delivery. 5 The fetuses with absent diastole / reversed diastolic flow on follow up have sequelae of neurological deficit in high proportions. Umbilical artery doppler study reflects disease severity in small for gestational age fetuses and is not independently associated with neonatal outcome. Umbilical flow velocimetry studies should be an integral parameter while evaluating the in-utero health of the growth restricted fetuses.

\section{Funding: No funding sources \\ Conflict of interest: None declared}

Ethical approval: The study was approved by the Institutional Ethics Committee

\section{REFERENCES}

1. Divon M, HSU H. Maternal and Fetal Blood Flow Velocity Waveforms in Intrauterine Growth Retardation. Clinical Obstetr Gynecol. 1992;35(1):156-71.

2. Ido P, Gale R, Laor A, Danon Y, Stevenson D, Seidman D. The cognitive outcome of full-term small for gestational age infants at late adolescence. Obstetr Gynecol. 1995;85(3):452-6.

3. Piper J, Xenakis E, Mcfarland M, Elliott B, Berkus M, Langer O. Do growth-retarded premature infants have different rates of perinatal morbidity and mortality than appropriately grown premature infants?. Obstetrs Gynecol. 1996;87(2):169-74.

4. Newnham JP, Godfrey M, Walters BJ, Phillips J, Evans SF. Low dose aspirin for the treatment of fetal growth restriction: a randomized controlled trial. Aust N Z J Obstet Gynaecol. 1995;35(4):370.

5. Fleischer A, Schulman H, Farmakides G, Bracero L, Blattner P, Randolph G. Umbilical artery velocity waveforms and intrauterine growth retardation. Americ J Obstetr Gynecol. 1985;151(4):502-5.

6. Chanana C, Kumar S, Roy K, Sharma J, Malhotra N. Comparison of perinatal outcome of growthrestricted fetuses with normal and abnormal umbilical artery Doppler waveforms. Ind J Medic Sci. 2006;60(8):311.

7. Vergani P, Andreotti C, Roncaglia N, Zani G, Pozzi E, Pezzullo J, et al. Doppler predictors of adverse neonatal outcome in the growth restricted fetus at 34 weeks' gestation or beyond. Americ J Obstet Gynecol. 2003;189(4):1007-11. 
8. McCowan L, Harding J, Stewart A. Umbilical artery Doppler studies in small for gestational age babies reflect disease severity. BJOG: An International J Obstetr Gynaecol. 2000;107(7):916-25.

9. Owen P, Harrold A, Farrell T. Fetal size and growth velocity in the prediction of intrapartum caesarean section for fetal distress. BJOG: An International J Obstetr Gynaecol. 1997;104(4):445-9.

10. Owen P, Khan K. Fetal growth velocity in the prediction of intrauterine growth retardation in a low risk population. BJOG: An Internat J Obstetr Gynaecol. 1998;105(5):536-40.

11. Soregaroli M, Bonera R, Danti L, Dinolfo D, Taddei F, Valcamonico A, et al. Prognostic role of umbilical artery Doppler velocimetry in growth-restricted fetuses. The Journal of Maternal-Fetal and Neonatal Medic. 2002;11(3):199-203.

12. Baschat A, Gembruch U, Reiss I, Gortner L, Weiner C, Harman C. Relationship between arterial and venous Doppler and perinatal outcome in fetal growth restriction. Ultrasound Obstet Gynecol. 2000;16(5):407-13.

Cite this article as: Thomas JS, Malliga A, Sethurajan S. Significance of umbilical artery doppler velocimetry in the perinatal outcome of growth restricted fetuses. Int J Reprod Contracept Obstet Gynecol 2018;7:1074-8. 